\title{
EVOLUÇÃO ESPAÇO-TEMPORAL DO ALBEDO E DA COBERTURA VEGETAL DA SUPERFÍCIE NA BACIA HIDROGRÁFICA DO ALTO CURSO DO RIO PARAÍBA
}

\author{
Telma Lucia Bezerra Alves ${ }^{1}$ \\ Pedro Vieira de Azevedo ${ }^{2}$ \\ Carlos Antonio Costa dos Santos ${ }^{3}$ \\ Francineide Amorim Costa Santos ${ }^{4}$
}

\begin{abstract}
Resumo: O presente estudo teve como objetivo analisar a variação espaço-temporal do albedo e da cobertura vegetal da superfície na bacia hidrográfica do alto curso do Rio Paraíba, como importantes indicadores do processo de degradação das terras/desertificação. As informações das duas variáveis foram obtidas de 168 imagens MODIS (Moderate Resolution Imaging Spectro radiometer), correspondentes aos doze meses do ano no período de 20002013. O teste Mann-Kendall (MK) foi utilizado para identificação da tendência, ao nível de significância de $\alpha=0,05$. Os principais resultados evidenciaram que os valores médios do albedo da superfície variam entre 11 e $21 \%$, com máximos em fevereiro e mínimos em julho. Os valores médios mensais do IVAS variaram entre 0,18 e 0,36, com máximos em abril e mínimos em outubro. A precipitação pluvial é a variável que condiciona a variação do índice de vegetação e do albedo na região. Os municípios de São Sebastião do Umbuzeiro e Congo apresentaram, respectivamente, os maiores e menores valores médios do IVAS, em virtude das características climáticas e do relevo do primeiro município, com altitudes mais elevadas, que propiciam mais umidade. O município de Congo apresentou os menores valores de IVAS $(0,15)$, sendo possível identificar uma correlação inversa com os valores de albedo da superfície.
\end{abstract}

Palavras-chave: Degradação das terras; Precipitação pluvial; Sensoriamento remoto

\section{EVOLUTION SPATIOTEMPORAL OF THE ALBEDO AND SURFACE VEGETATION COVER IN THE WATERSHED OF THE UPPER COURSE OF PARAÍBA RIVER}

\begin{abstract}
This study aimed to analyze the spatial and temporal variation of surface albedo and vegetation in the river basin of the upper course of the River Paraíba, as important indicators of the process of land degradation/desertification. The information of the two variables were obtained from 168 Modis (Moderate Resolution Imaging Spectro Radiometer), covering the period 2000-2013, for the months of each year of the series. The Mann-Kendall test (MK) was used to confirm the trend, for $\alpha=0.05$ level of significance. The main results show that the average of the surface albedo values range between 11 and $21 \%$, with peaks in February and minimum in July. The monthly average values of SAVI ranged from 0.18 to

\footnotetext{
1 Prof $^{\text {a }}$ de Geografia do Instituto Federal de Alagoas - IFAL, Dra. em Recursos Naturais. Email: telmaluciax@ hotmail.com

${ }^{2}$ Prof. Dr. da Unidade Acadêmica de Ciências Atmosféricas - UFCG. Email: pvdeazevedo@gmail.com

3 Prof. Dr. da Unidade Acadêmica de Ciências Atmosféricas - UFCG. Email: carlostorm@gmail.com

${ }^{4}$ Prof $^{a}$ do curso de Licenciatura Interdisciplinar em Ciências Naturais - UFCA, Dra. em Meteorologia. Email: francyacs@hotmail.com
} 
0.36, with maximum in April and minimum in October. Rainfall is the variable that determines the variation in vegetation index and albedo in the region. The municipalities of São Sebastião do Umbuzeiro, Congo presented the lowest, and highest average valuesof albedo, respectively, due to climatic conditions and relief of the first city, with higher elevations, which provide more moisture. The municipality of Congo also had the lowest values of SAVI (0.15), showing an inverse correlation with the albedo values of the surface that results from the sparse or no vegetation.

Keywords: Land degradation; Rainfall; Remote sensing

\section{EVOLUCIÓN ESPACIO-TEMPORAL DEL ALBEDO Y DE LA CUBIERTA VEGETAL DE LA SUPERFICIE EN LA BACIA HIDROGRÁFICA DEL ALTO CURSO DEL RÍO PARAÍBA}

Resumen: El presente estudio tuvo como objetivo analizar la variación espacio-temporal del albedo y de la cobertura vegetal de la superficie en la cuenca hidrográfica del alto curso del Río Paraíba, como importantes indicadores del proceso de degradación de las tierras / desertificación. La información de las dos variables fue obtenida de 168 imágenes MODIS (Moderate Resolution Imaging Spectro radiometer), correspondientes a los doce meses del año en el período 2000-2013. La prueba Mann-Kendall (MK) se utilizó para identificar la tendencia, al nivel de significancia de $\alpha=0,05$. Los principales resultados evidenciaron que los valores medios del albedo de la superficie varían entre 11 y $21 \%$, con máximos en febrero y mínimos en julio. Los valores medios mensuales del IVAS variaron entre 0,18 y 0,36, con máximos en abril y mínimos en octubre. La precipitación pluvial es la variable que condiciona la variación del índice de vegetación y del albedo en la región. Los municipios de São Sebastião del Umbuzeiro y Congo presentaron, respectivamente, los mayores y menores valores medios del IVAS, en virtud de las características climáticas y del relieve del primer municipio, con altitudes más elevadas, que propician más humedad. El municipio de Congo presentó los menores valores de IVAS $(0,15)$, siendo posible identificar una correlación inversa con los valores de albedo de la superficie.

Palabras clave: Degradación de las tierras; Precipitación pluvial; Detección remota

\section{INTRODUÇÃO}

$\mathrm{O}$ uso inadequado dos recursos naturais tem conduzido o atual modelo de desenvolvimento da sociedade a uma situação insustentável. No âmbito das bacias hidrográficas brasileiras, essa afirmativa é uma realidade, principalmente por serem unidades que agregam recursos naturais e ações antrópicas mal planejadas (BOTELHO \& SILVA, 2004).

No semiárido brasileiro as bacias hidrográficas e seus recursos naturais vêm sendo degradados e pouco priorizados, em comparação aos interesses econômicos. Ações como: pastoreio intensivo, uso da vegetação nativa como fonte energética, retirada da mata ciliar, agricultura tradicional, aliadas a características naturais como: declividades acentuadas, precipitações torrenciais e secas extremas, dentre outras, promovem a degradação das 
terras/desertificação. Os estudos até então realizados (Sales (2002); Conti, 2005; Brasil, 2004; Souza et. al., 2004; Alves et al., 2009; Souza et.al., 2010) têm diagnosticado áreas em processo de desertificação na região Nordeste, particularmente no estado da Paraíba, incluindo algumas inseridas na região do alto curso do Rio Paraíba.

Em virtude da importância e dos reduzidos dados de campo para monitorar a variação espaço-temporal da Caatinga em regiões semiáridas do Nordeste brasileiro, pesquisas com sensoriamento remoto permitem compreender o comportamento dos parâmetros biofísicos, no contexto das ações antropogênicas. A análise da vegetação por meio de uma única imagem limita a extração de várias informações desta, pois a mesma representa a cena de uma única data da passagem do satélite. Contudo, a utilização de uma série multitemporal, permite o acompanhamento da biomassa verde e estrutura da vegetação. A identificação e eliminação dos fatores que contribuem para a degradação das terras é a forma mais eficaz de reverter os prejuízos ambientais, auxiliando no planejamento adequado do uso da água, do solo, da vegetação, enfim, de todos os recursos naturais disponíveis (CASTANHO et al., 2004; MAGALHÃES et al., 2013; BEZERRA et al., 2014).

De acordo com Ponzoni et al., (2012) diversos índices de vegetação têm sido propostos na literatura com o objetivo de explorar as propriedades espectrais da vegetação, especialmente nas regiões do visível e do infravermelho próximo. Esses índices são relacionados a parâmetros biofísicos da cobertura vegetal, como biomassa e índice de área foliar, declividade da superfície e geometria de aquisição, que influenciam os valores de refletância da vegetação. Os autores explicam que quanto maior for à densidade da cobertura vegetal de uma determinada área, maior será a absortância na região do visível, em razão da maior oferta de pigmentos fotossintetizantes. Por outro lado maior será a refletância verificada na região do infravermelho próximo, por causa do espalhamento múltiplo da radiação eletromagnética na estrutura foliar das plantas.

Os principais índices de vegetação disponíveis na literatura são: Índice de vegetação da razão simples (IVRS), Índice de vegetação da diferença normalizada (IVDN), Índice de vegetação perpendicular (IVP), Índice de vegetação ajustado para o solo (IVAS); Índice de vegetação resistente à atmosfera (IVAA), Índice global de monitoramento ambiental (IGMA) e Índice de vegetação melhorado (IVM). Em geral, a mudança na vegetação é o indicador mais direto da degradação do solo e da variação sensível no ambiente causada pela desertificação. No entanto, não se recomenda uma avaliação baseada apenas nas mudanças do 
crescimento da vegetação, pois existem vários estados estáveis para a vegetação em ecossistemas áridos (YANG et al., 2004).

$\mathrm{O}$ albedo, comumente dado em porcentagem, se caracteriza pela capacidade que os corpos têm de refletir a radiação solar que incide sobre eles e varia de acordo com a cor e a constituição do corpo. Assim, será máximo nos corpos brancos e mínimo nos corpos pretos. Nas superfícies planas e horizontais não vegetadas, o albedo varia com as propriedades físicas dos materiais que as constituem (cor, rugosidade, etc.) e com o ângulo zenital do Sol, sendo menor quando este astro se encontra próximo à culminação. Havendo vegetação, o albedo varia com a espécie, a fase do desenvolvimento, o estado de sanidade, a geometria da copa, o índice de área foliar, etc. O albedo da superfície é definido como a razão entre as irradiâncias refletida e incidente. Em geral, o termo albedo, usado na literatura meteorológica, considera a radiação de onda curta, aproximadamente entre 0,15 e 4,0 $\mu \mathrm{m}$ (VAREJÃO-SILVA, 2006; MENDOÇA \& DANNI-OLIVEIRA, 2007; GIONGO \& VETTORAZZI, 2014).

Conti (2011) explica que com o desmatamento, surgem grandes extensões de solo nu, fato que contribui para mudar a refletância da superfície, aumentando os valores do albedo. Isso leva a redução da energia térmica disponível - processo agravado pela ausência de nebulosidade, que favorece o escape da radiação infravermelha originada na superfície. $\mathrm{O}$ resultado é a não formação de correntes convectivas ascendentes, condição desfavorável à formação de chuvas, processo chamado pelos cientistas de mecanismo biogeofísico de feedback (retroalimentação).

Estudos sobre o emprego de técnicas de sensoriamento remoto para análise da dinâmica da cobertura vegetal, albedo da superfície e avaliação das áreas de degradação das terras/desertificação são observados em: Li et al., 2000; Accioly et al., 2002; Barbosa et al., 2006; Govaerts \& Lattanzio, 2008; Rodrigues et al., 2009; Lopes et al., 2010; Sá et al., 2010; Melo et al., 2011; Aquino et al., 2012; Cunha et al., 2012.

Assim, o presente estudo objetivou a análise da evolução espaço-temporal do albedo e cobertura vegetal da superfície, para fins de avaliação da degradação das terras/desertificação na bacia hidrográfica do alto curso do Rio Paraíba.

\section{MATERIAIS E MÉTODOS}

\section{Área de estudo}

O presente estudo foi realizado na bacia hidrográfica do alto curso do Rio Paraíba, limitando-se ao Norte com a sub-bacia do Rio Taperoá, ao Sul e a Oeste com o estado de Pernambuco e a Leste com a região do médio curso do Rio Paraíba (Figura 1). A bacia 
hidrográfica do alto curso do Rio Paraíba tem uma área de aproximadamente $6.727,69 \mathrm{~km}^{2} \mathrm{e}$ engloba, total ou parcialmente, a área de 18 municípios distribuídos nas microrregiões do Cariri Ocidental e Oriental do estado da Paraíba.

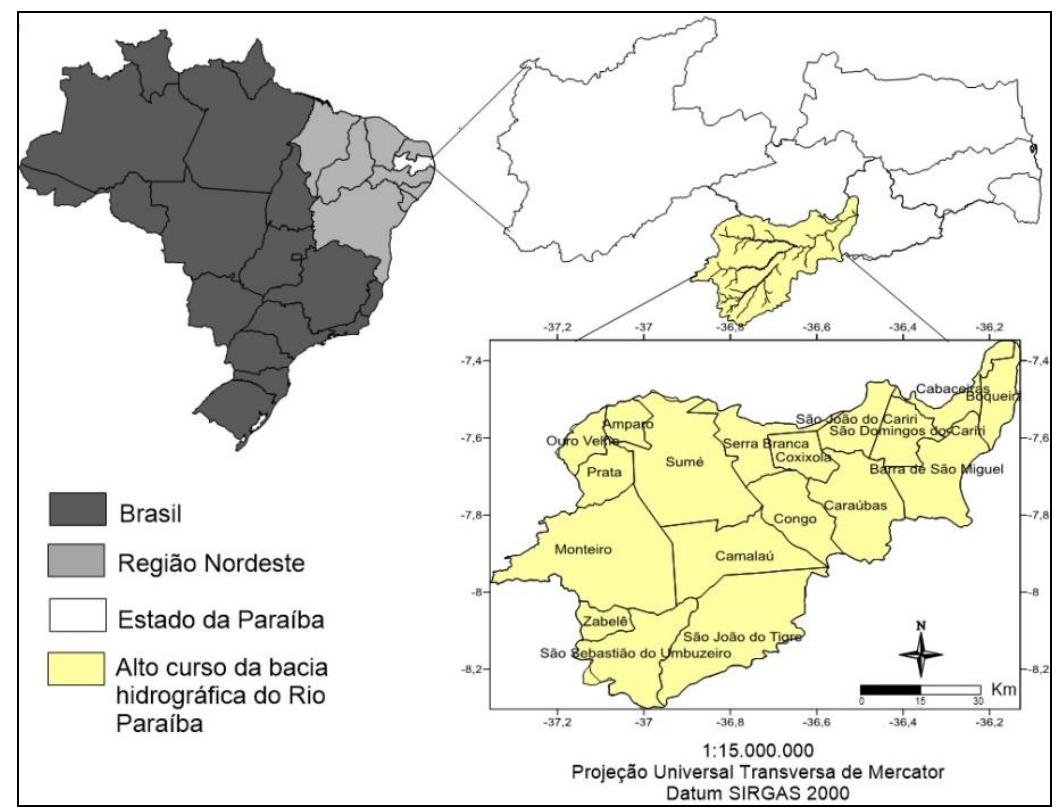

Figura 1: Localização geográfica da bacia hidrográfica do alto curso do Rio Paraíba, estado da Paraíba.

\section{DADOS UTILIZADOS}

Foram utilizadas imagens digitais orbitais MODIS (Moderate Resolution Imaging Spectroradiometer), para obtenção dos índices de vegetação e do albedo da superfície, disponíveis em grande quantidade, pois a resolução temporal é diária. O sensor MODIS é um instrumento fundamental a bordo dos satélites Terra - Aqua.

As imagens foram obtidas gratuitamente no portal da National Aeronautics and Space Administration (NASA). Devido a oferta de um produto melhorado a cada oito dias, optou-se pelo produto MOD09A1, considerado mais adequado para o monitoramento dos parâmetros estudados. Este produto é oriundo da refletância da superfície, disponível no MODLAND para o continente sul-americano.

Os dados MODIS foram obtidos originalmente na projeção integerized sinusoidal e no formato Hierarquical Data Format (HDF), sendo convertidos para o sistema de coordenadas geográficas, projeção WGS, e formato IMG através do ERDAS Imagine 8.5. Além disso, todas as rotinas computacionais necessárias à geração do IVAS e do albedo da superfície foram executadas no módulo Model Maker deste programa. A área de estudo está inserida no tile v9_h12. Foi analisado um dia juliano de cada mês, selecionados devido à ausência de 
nuvens e por representarem sequencialmente os meses da série temporal 2000-2013. As informações espectrais foram obtidas para cada município, através da delimitação dos mesmos, em formato aoi.

A Tabela 1 descreve o produto MODIS utilizado no presente estudo, com o fator de correção multiplicativo que é empregado para converter os valores originais em dados de refletância (adimensional):

Tabela 1: Descrição do produto MODIS utilizado.

\begin{tabular}{ccccc}
\hline Produto & Descrição & $\begin{array}{c}\text { Fator } \\
\text { multiplicativo }\end{array}$ & $\begin{array}{c}\text { Resoluçãa espacial/ } \\
\text { temporal }\end{array}$ & Unidades \\
\hline MOD09A1 & $\begin{array}{c}\text { Reflectância } \\
\text { da superfície }\end{array}$ & 0,0001 & $\begin{array}{c}500 \mathrm{~m} \\
\text { diária/composição de 8 } \\
\text { dias }\end{array}$ & Adimensional \\
\hline
\end{tabular}

Fonte: http://modis.gsfc.nasa.gov/

As características da vegetação bem como o uso e ocupação do solo foram investigados por meio de visitas técnicas ao campo, para seleção de pontos controle que representem a diversidade do que se deseja investigar/mapear. Este procedimento orientou a análise das imagens orbitais. Tais visitas foram realizadas em:

- Junho e setembro de 2012: onde foram visitadas várias áreas nos municípios de Caraúbas, Congo, São Domingos do Cariri, Sumé, Camalaú e Monteiro.

- Dezembro de 2014 foi feito um trabalho de campo em todos os municípios, com o reconhecimento de aspectos da vegetação e georeferenciamento de áreas em processo de degradação.

\section{Índice de vegetação}

O índice de vegetação ajustado ao solo (IVAS), o qual varia de $-1 \mathrm{a}+1$, sendo positivo para superfícies com alguma vegetação e negativo para superfícies livres de água (espelhos de água), foi obtido como (PONZONI et al., 2012):

$$
I V A S=\frac{\left(\rho_{I V P}-\rho_{V}\right)(1+L)}{\left(\rho_{I V P}+\rho_{V}+L\right)}
$$

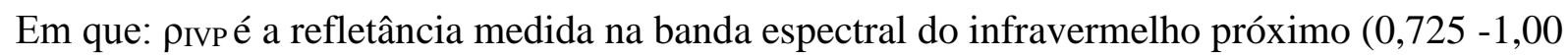
$\mu \mathrm{m})$ e $\rho_{\mathrm{V}}$ a refletância medida na banda espectral do visível (vermelho) $(0,625-0,725 \mu \mathrm{m})$ e $\mathrm{L}$ é a constante que minimiza o efeito do solo e pode variar de 0 a 1 . Neste caso foi utilizado o valor 0,5. Para baixa, média e alta densidade de vegetação, recomendam-se os fatores $\mathrm{L}=1, \mathrm{~L}$ $=0,5$ e L $=0,25$, respectivamente (PONZONI et al., 2012; SILVA, 2009). Neste trabalho, o uso do IVAS permitiu comparar a cobertura vegetal atual com a vegetação pretérita, em uma 
análise de evolução temporal, considerando-se as características específicas da sazonalidade na área de estudo.

\section{Albedo da Superfície}

O albedo da superfície foi determinado como (Tasumi et al., 2008):

$$
\alpha_{T}=\sum_{b=1}^{n}\left[\rho_{s, b} w_{b}\right]
$$

Em que os pesos $w_{b}$ são os coeficientes de ponderação que representam a fração da radiação solar que ocorre no intervalo espectral das bandas específicas, constantes na Tabela $2 ; n$ o número de bandas correspondente e $\rho_{s, b}$ a refletância espectral à superfície, obtida do produto MOD09A1.

Tabela 2: Coeficientes de ponderação $\left(w_{b}\right)$ da Equação (2), para uso em imagens MODIS

\begin{tabular}{lccccccc}
\hline Coeficiente & \multicolumn{7}{c}{ Bandas } \\
\hline$w_{b}$ & $\mathbf{1}$ & $\mathbf{2}$ & $\mathbf{3}$ & $\mathbf{4}$ & $\mathbf{5}$ & $\mathbf{6}$ & $\mathbf{7}$ \\
\hline & 0,215 & 0,215 & 0,242 & 0,129 & 0,101 & 0,062 & 0,036 \\
\hline
\end{tabular}

A escolha do método proposto por Tasumi et. al. (2008) deve-se ao fato de ter sido calibrado e aplicado na região de Idaho - USA, área de risco moderado ao processo de desertificação e por ser uma metodologia mais recente.

\section{Análise estatística}

Vários parâmetros estatísticos foram utilizados para analisar os padrões espaciais e temporais da heterogeneidade da vegetação na superfície da bacia hidrográfica. As análises foram realizadas temporalmente, obtendo-se o valor mínimo, médio, máximo e o coeficiente de variação $(\mathrm{CV})$ dos valores mensais de IVAS obtidos durante o período da série de anos (2000-2013). Foram traçadas curvas temporais estatísticas ao longo dos 12 meses para capturar respostas do ecossistema e da paisagem para as grandes variações (eventos chuvosos, secas extremas e cheias), que não podem ser evidentes em valores médios (KOGAN, 2000).

\section{Teste de Mann-Kendall}

As séries temporais do Albedo e do IVAS foram analisadas pelo teste de MannKendall (BACK, 2000). Esse teste consiste em comparar cada valor da série temporal com os valores restantes, sempre em ordem sequencial. É contado o número de vezes que os termos restantes são maiores do que o valor analisado. A estatística $S$ é obtida pela soma de todas as contagens, como segue: 


$$
\mathrm{S}=\sum_{\mathrm{i}=2}^{\mathrm{n}} \sum_{\mathrm{j}=1}^{\mathrm{i}=1} \sin \mathrm{al}\left(\mathrm{x}_{\mathrm{i}}-\mathrm{x}_{\mathrm{j}}\right)
$$

Em que o $\sin a l\left(x_{\mathrm{i}}-\mathrm{x}_{\mathrm{j}}\right)$ é obtido da seguinte forma:

$$
-1 \text {, para } x_{i}-x_{j}<0 ; 0 \text {, para } x_{i}-x_{j}=0 ; 1 \text {, para } x_{i}-x_{j}>0
$$

A estatística $\mathrm{S}$ tende a normalidade para $n$ grande, com média e variância definidas como:

$$
\mathrm{E}[\mathrm{S}]=0, \text { e } \operatorname{Var}(S)=\frac{1}{18}\left[n(n-1)(2 n+5)-\sum_{p-1}^{q} t_{p}\left(t_{p-1}\right)\left(2 t_{p}+5\right)\right]
$$

Em que: $n$ é o tamanho da série temporal; $t_{p}$ é o número de passos até o valor; $p$ e $q$ são os números de valores iguais. $\mathrm{O}$ teste estatístico $\mathrm{Z}$ é dado por:

$$
Z=\left\{\begin{array}{cc}
\frac{S-1}{\sqrt{\operatorname{Var}(S)}} & \text { se } S>0 \\
0 & \text { se } S=0 \\
\frac{S-1}{\sqrt{\operatorname{Var}(S)}} & \text { se } S<0
\end{array}\right.
$$

A presença de uma tendência estatisticamente significante na série temporal será avaliada usando-se o valor da estatística Z, usada para testar a hipótese nula de que nenhuma tendência existe. Valores positivos de $\mathrm{Z}$ indicam tendências crescentes, enquanto que negativos indicam tendências decrescentes. Para testar qualquer tendência, crescente ou decrescente, para um nível significante $\alpha$, rejeita-se a hipótese nula se o valor absoluto de $\mathrm{Z}$ for maior que $\mathrm{Z}_{1-\alpha / 2}$, obtido na tabela da distribuição normal. Neste trabalho, foi aplicado o nível de significância $\alpha=0,05$. Assim, se Z for maior que 1,96 , rejeita-se a hipótese nula ao nível de $5 \%$ e as médias são estatisticamente diferentes. Para se compreender melhor o valor do teste é apresentado uma legenda para os valores (Tabela 3):

Tabela 3: Descrição da legenda correspondente à significância do teste Mann-Kendall

\begin{tabular}{l|c|c}
\hline \multicolumn{1}{c|}{ Significância } & Legenda & $\mathbf{Z}$ \\
\cline { 2 - 3 } Sem tendência & St & 0 \\
Tendência significativa crescente & Tsc & $>+1,96$ \\
Tendência significativa decrescente & Tsd & $<-1,96$ \\
Tendência não-significativa crescente & Tnsc & $<+1,96$ \\
Tendência não-significativa decrescente & Tnsd & $>-1,96$ \\
\hline
\end{tabular}

Fonte: Alves, Azevedo e Farias (2015). 


\section{RESULTADOS E DISCUSSÃO}

Análise da evolução temporal do albedo e cobertura vegetal da superfície

Os valores máximos do índice de vegetação ajustado ao solo (IVAS) ocorreram no trimestre mais chuvoso para a região (fevereiro-março-abril (Figura 2A). Os picos encontrados após a estação chuvosa são decorrentes do tempo necessário para a recuperação do porte e densidade da vegetação. Os anos de 2008 e 2009 apresentaram os maiores valores do IVAS. Os meses de setembro e outubro apresentam os valores mínimos, com redução da biomassa, que somente vai se recuperar meses depois da estação chuvosa. Ao longo do ano, os valores médios mensais do IVAS variaram entre 0,18 e 0,36. Nos anos de 2012 e 2013 a vegetação foi mais afetada pelas baixas precipitações ocorridas, que caracterizaram tais anos como secos. De modo geral, o índice mostrou um comportamento semelhante ao longo dos anos. As condições de maior e menor vigor da vegetação coincidem, respectivamente, com as estações chuvosa e seca na região de estudo. Barbosa et al., (2006) em estudo realizado para a região Nordeste do Brasil, analisando vinte anos de dados, encontraram curvas anuais de índice de vegetação com variações mensais semelhantes, mas com elevadas amplitudes. $\mathrm{O}$ índice de vegetação apresenta relação direta com a ocorrência da precipitação pluvial, cujas médias mensais para a região e sua relação com o IVAS e albedo podem ser observadas na Figura 3. A vegetação representa uma resposta direta à ocorrência da precipitação pluvial, que por sua vez é bastante variável no tempo e no espaço, na área de estudo.

Em relação ao albedo da superfície (Figura 2B), observa-se que os valores mínimos ocorrem nos meses do inverno (junho, julho e agosto), devido à cobertura vegetal e umidade do solo mais acentuadas. Nos demais meses os valores aumentam, atingindo valores máximos no mês de fevereiro. Ao longo do ano, os valores médios mensais do albedo variaram de 11 a 21\%, concordando com os valores observados para região de Caatinga (Lima et. al., 2009; Rodrigues et. al., 2009; Cunha et al., 2012 e Bezerra et al. 2014). O albedo aumenta com a diminuição da precipitação, numa relação indireta, visto que representa uma resposta dessa variável a redução da vegetação. 


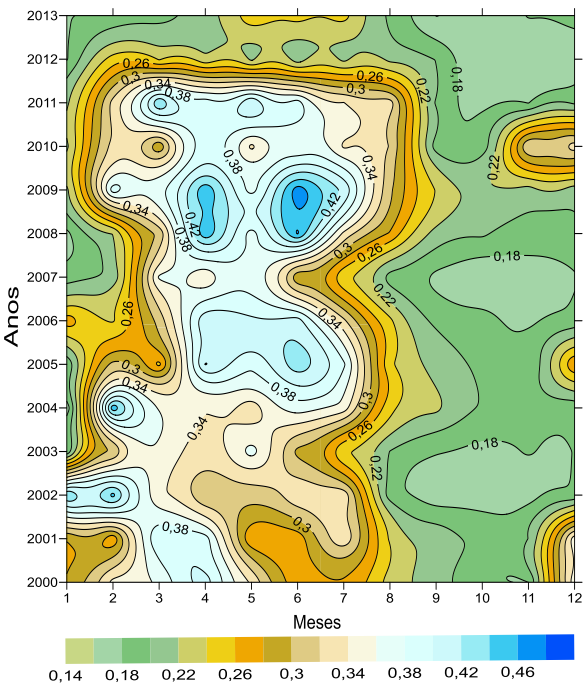

IVAS (A)

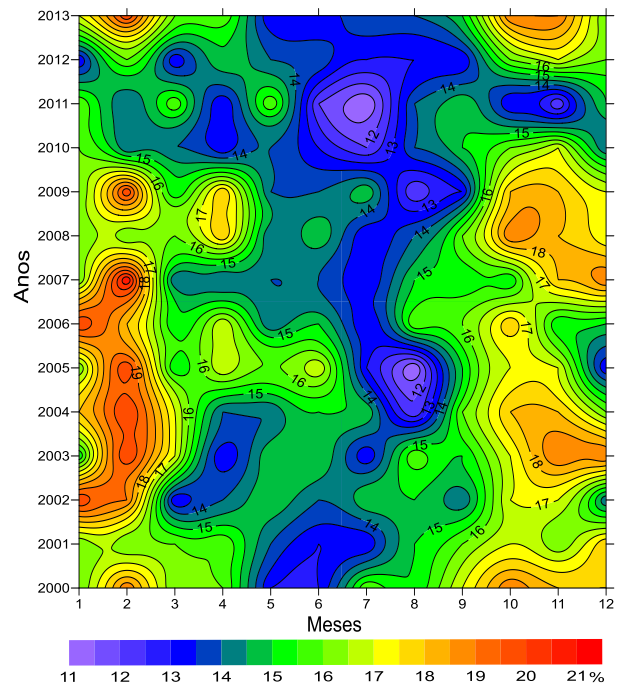

Albedo da Superfície (B)

Figura 2: Distribuição temporal dos valores médios do índice de vegetação ajustado ao solo IVAS (A) e do albedo da superfície (B) no período de janeiro de 2000 a dezembro de 2013.
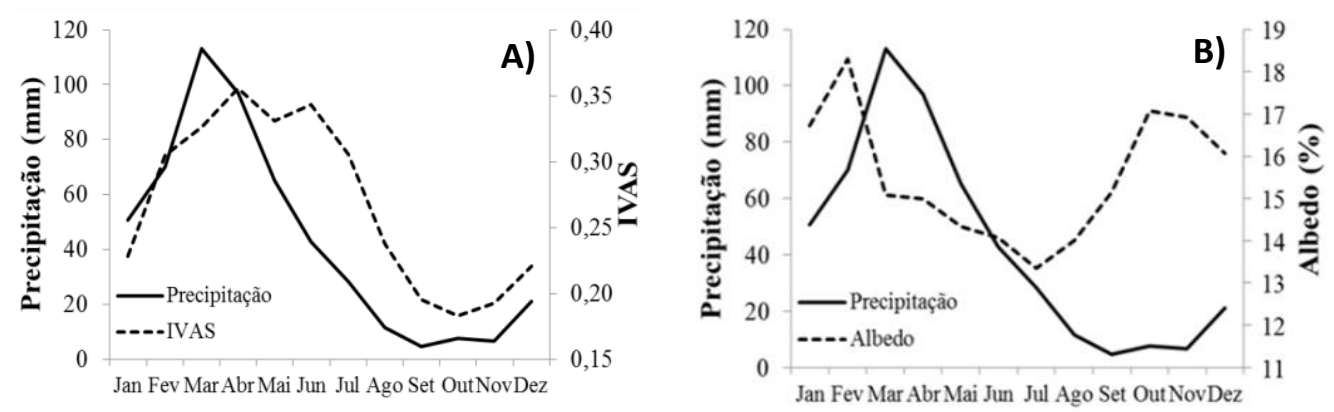

Figura 3: Média mensal da precipitação pluvial e sua relação com o índice de vegetação ajustado ao solo - IVAS (A) e Albedo da superfície (B) para a bacia hidrográfica do alto curso do Rio Paraíba.

As curvas inversas do albedo da superfície versus IVAS são apresentadas na Figura 4. Sabe-se que quando a vegetação está mais verde e densa reflete menos. À medida que a vegetação diminui ou perde sua folhagem (senescência), em decorrência do estresse hídrico da estação seca, a refletividade aumenta, pois o solo fica mais descoberto e as áreas mais claras. Por outro lado, quando a vegetação se desenvolve, nos meses da estação chuvosa, o albedo diminui consideravelmente. Assim, o monitoramento temporal e espacial desses parâmetros contribui para o entendimento e mensuração do processo de degradação das terras/desertificação, principalmente quando as causas da redução da vegetação são antrópicas. 


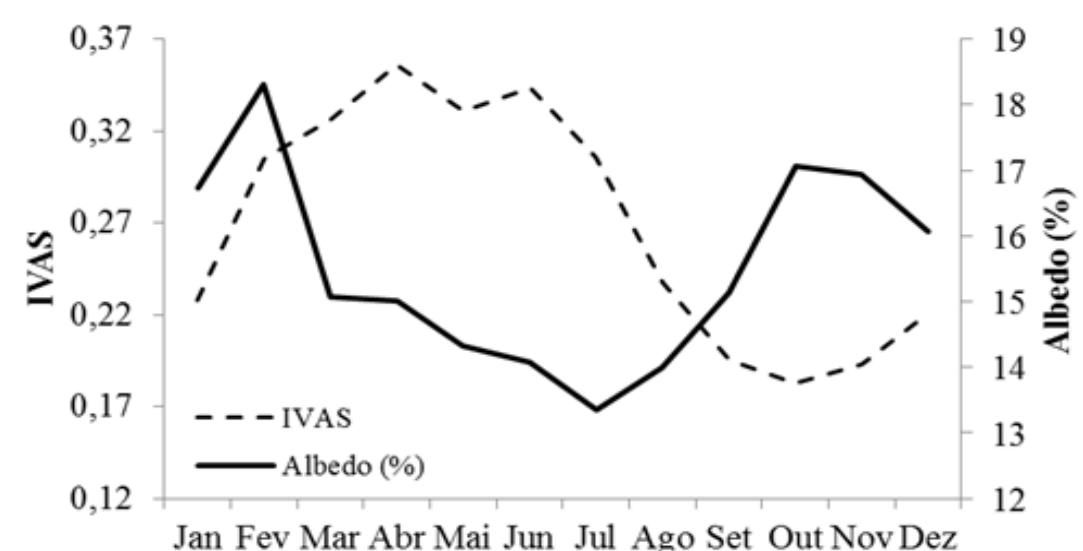

Meses (média 2000-2013)

Figura 4: Comportamento mensal do índice de vegetação ajustada ao solo - IVAS em comparação ao albedo da superfície para a região da bacia hidrográfica do alto curso do Rio Paraíba.

Esse comportamento inverso do albedo da superfície e o índice de vegetação também foi observado por Govaerts \& Lattanzio (2008) para a região do Sahel, durante o ano seco de 1984 e o ano chuvoso de 2003. A precipitação no Sahel ocorre de junho a outubro (JJASO) e determina a diminuição do albedo da superfície observada de agosto a outubro (ASO). Assim, variações sazonais do albedo da superfície são influenciadas pela precipitação. A estação seca, ocorrendo aproximadamente de outubro a abril, é caracterizada por um aumento lento do albedo na superfície resultante da senescência da vegetação, e os valores mínimos de albedo são atingidos no final da estação chuvosa, ou seja, aproximadamente em outubro. Santos et al. (2014) explicam que esta relação inversa entre índice de vegetação e albedo é devido à elevada taxa de radiação que é absorvida pela vegetação que é usada em seus processos biofísico-químicos como a respiração e transpiração. Quando a vegetação é removida e/ou perde suas folhas no período de estiagem, e o solo é assim exposto, a taxa de absorção da radiação solar é baixa, uma vez que estes são drasticamente reduzidos. Como resultado, altos níveis de energia são perdidos pela refletividade da superfície.

Na Figura 5 apresenta-se a análise dos valores mínimos, médios e máximos para o IVAS (A) e albedo (B), correspondendo à média dos 14 anos analisados. As três curvas dos índices acompanham as variações temporais semelhantes, no entanto, a amplitude sazonal nos valores máximos é bastante elevada. As curvas máxima e média de IVAS são elevadas em março, abril, maio, junho e julho e baixa nos meses de outubro, novembro e dezembro. A curva de Coeficiente de variação (CV) médio apresenta a oscilação de $10 \%$ a $40 \%$, indicando a variação sazonal média do índice de vegetação durante o período do estudo. Os maiores valores de CV, aproximadamente $30 \%$, são encontrados nos meses de dezembro e janeiro, 
pois ocorre elevada variabilidade em relação ao início da estação chuvosa, enquanto os menores valores, em torno de $10 \%$, ocorrem nos meses mais secos (setembro e outubro), período do ano em que invariavelmente a vegetação está mais seca e perde suas folhas. Os valores médios mensais de IVAS variam de 0,15 a 0,35 , com valores médios de 0,27 . O coeficiente de variação (CV) do índice de vegetação foi sempre mais elevado do que o albedo (Figura 5B), evidenciando que a variabilidade destes valores, uma resposta à irregularidade espaço-temporal da precipitação pluvial. Os valores de albedo apresentam amplitude bem menor que os índices de vegetação (Figura 5B) e o CV mais elevado também ocorreu nos meses de janeiro e fevereiro, em resposta a variação dos índices de vegetação. Resultados semelhantes foram encontrados por Machado et. al., (2011) para a região semiárida paraibana, com valores médios variando de 0,15 a 0,27. Barbosa et al., (2006) relatam que, em análises de 20 anos de dados de IVDN para o Nordeste Brasileiro (NEB), foram identificadas fortes oscilações temporais e espaciais. A análise temporal mostrou que a forma geral de oscilações do IVDN é sazonal, sendo largamente influenciada pelos períodos secos e chuvosos. Barbosa (2013) confirma uma variação média do IVDN de 0,30 a 0,70 para o NEB, determinando desde áreas desnudas-degradadas a áreas com cobertura vegetal densa. Ressalta-se que, mesmo sendo utilizado outro índice de vegetação, que não considera a refletividade do solo e, portanto, apresenta valores mais elevados que o IVAS, a comparação é válida devido à observação da variação sazonal.
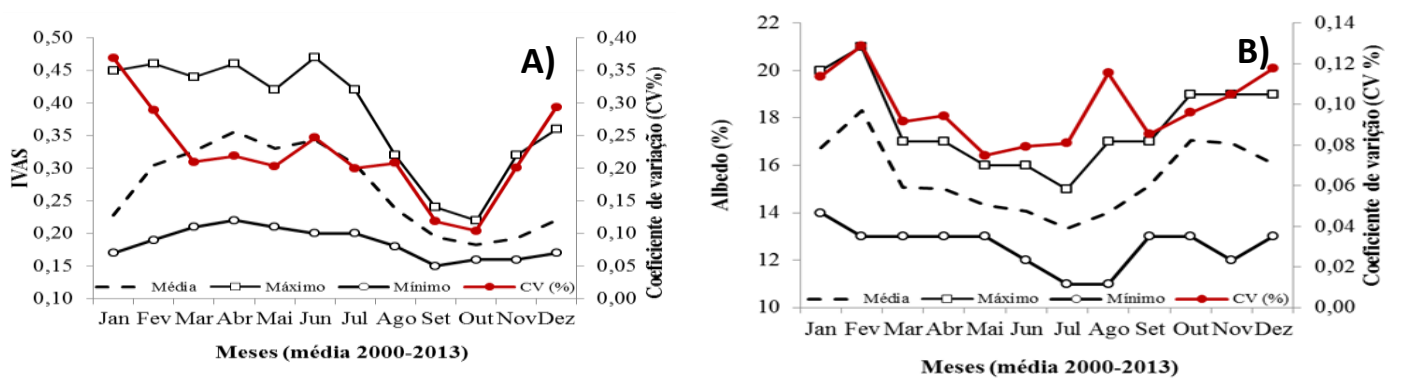

Figura 5: Curvas dos valores mínimos, médios, máximos e do CV do Índice de vegetação ajustado ao solo - IVAS (A) e do albedo da superfície (B) para o alto curso da bacia hidrográfica do Rio Paraíba, período 2000-2013.

O comportamento das variáveis (precipitação pluvial, albedo e índice de vegetação) para os municípios que apresentaram valores extremos (Congo e São Sebastião do Umbuzeiro) é apresentado na Figura 6. Uma das causas dessa diferença deve-se aos valores médios precipitados em cada município, pois, enquanto Congo tem uma média de $504 \mathrm{~mm}$ de precipitação anual, São Sebastião do Umbuzeiro tem $568 \mathrm{~mm}$, sendo essa diferença (64 mm) 
refletida no desenvolvimento da vegetação. Além disso, fatores relacionados ao relevo contribuem para as condições mais favoráveis a umidade no município de São Sebastião do Umbuzeiro, com altitude superior a $700 \mathrm{~m}$, comparada à altitude do município de Congo, em torno de $500 \mathrm{~m}$.

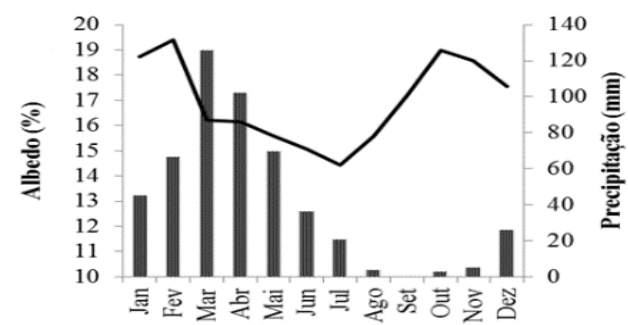

A)

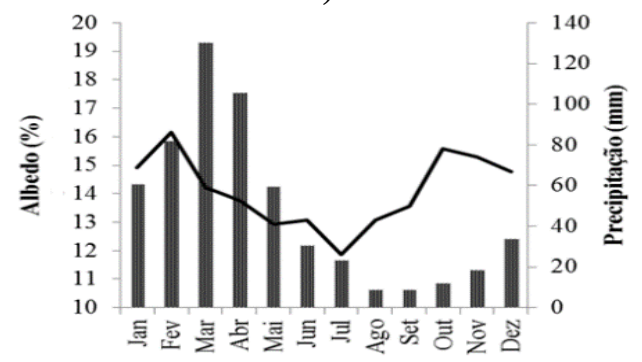

C)

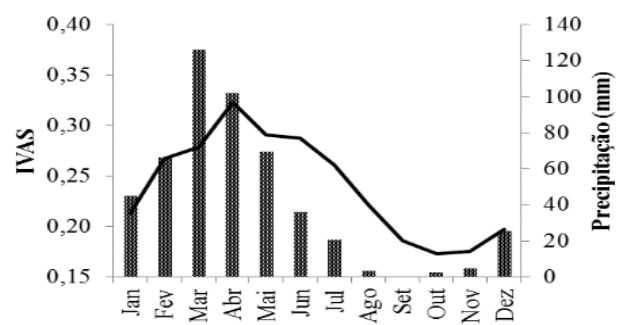

B)

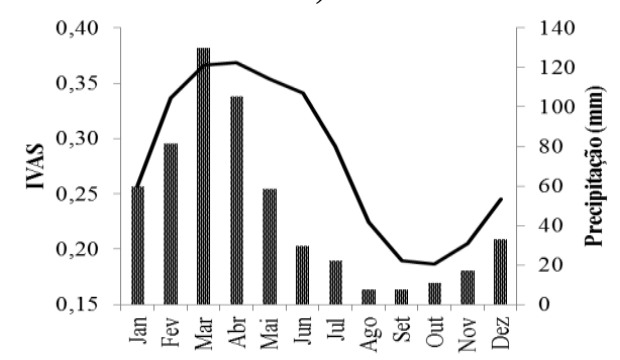

D)

Figura 6: Comportamento do índice de vegetação ajustado ao solo (IVAS) e do albedo da superfície em relação à precipitação pluvial (representada em barras) para os municípios de Congo (A e B) e São Sebastião do Umbuzeiro (C e D).

Observou-se que o valor mínimo de albedo da superfície foi identificado no município de São Sebastião do Umbuzeiro (12\%) no ano de 2011; o valor máximo (18\%) foi observado nos municípios de Congo. O município com menor valor de albedo da superfície apresentou maior índice de vegetação (São Sebastião do Umbuzeiro) e vice-versa (Congo), evidenciando novamente a inversabilidade das duas variáveis. Santos et al., (2014) encontraram para a região de Gilbués (PI), valores de albedo variando entre 19 e $42 \%$ para o dia 19 de agosto de 1994 e entre 26 e $50 \%$ em 15 de agosto de 2010.

Analisando a tendência geral dos valores médios anuais do índice de vegetação e albedo (Figura 7A e B), constatou-se, com base na estatística Z, que há uma tendência não significativa de decréscimo para as duas variáveis. Essas tendências decrescentes são explicadas, em parte, pelos anos secos de 2012 e 2013, nos quais a vegetação foi bastante afetada pela escassez de chuvas. 

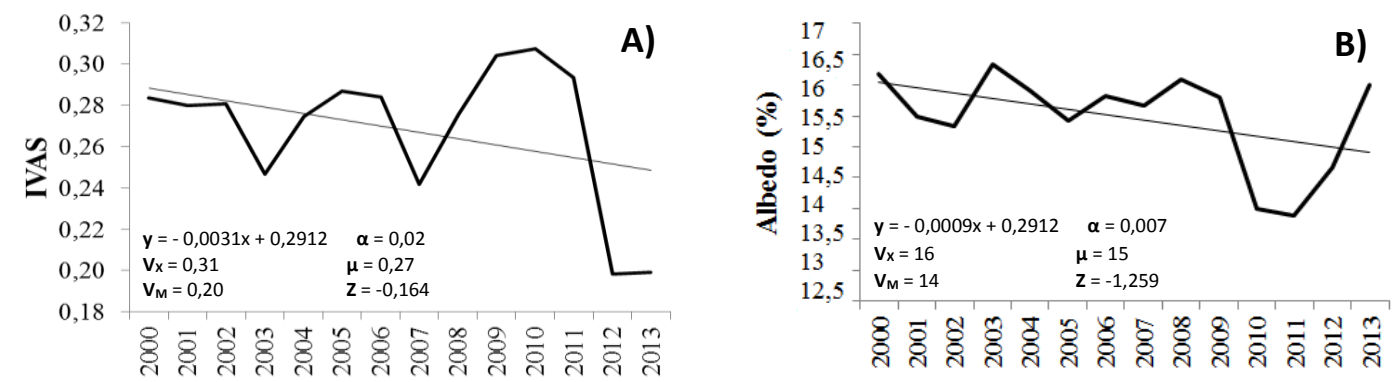

Figura 7: Evolução temporal do índice de vegetação ajustado ao solo - IVAS (A) e Albedo da superfície (B) na bacia hidrográfica do alto curso do Rio Paraíba, no período (2000-2013).

Na Tabela 4 apresenta-se o teste de tendência (MK) por município. Observa-se que, somente os municípios de Serra Branca e Coxixola não apresentaram tendência negativa para o IVAS. Porém, nenhuma das tendências foi significativa. Em relação ao albedo da superfície há uma tendência geral de diminuição desta variável ao longo do período estudado, porém com significância apenas para o município de Boqueirão e Cabaceiras. Para esses dois municípios, principalmente para o município de Boqueirão, em consequência da existência de cultivos permanentes irrigados nas margens do Reservatório Epitácio Pessoa.

Tabela 4: Análise da tendência do índice de vegetação ajustada ao solo (IVAS) e do albedo da superfície pelo teste de Mann Kendall (MK).

\begin{tabular}{l|cc|cc}
\hline \multirow{2}{*}{ Municípios } & \multicolumn{2}{|c|}{ IVAS } & \multicolumn{2}{c}{ Albedo } \\
\cline { 2 - 5 } & $\mathbf{Z}$ & $\mathbf{p}$-valor & $\mathbf{Z}$ & p-valor \\
\hline São João do Cariri & $-0,930$ & 0,352 & $-1,100$ & 0,270 \\
Serra Branca & 0,054 & 0,956 & $-0,990$ & 0,321 \\
Boqueirão & $-0,821$ & 0,411 & $-2,354^{*}$ & 0,018 \\
Prata & $-0,602$ & 0,547 & $-0,990$ & 0,321 \\
Monteiro & $-0,930$ & 0,352 & $-0,830$ & 0,406 \\
Sumé & $-0,164$ & 0,869 & $-1,336$ & 0,181 \\
Coxixola & 0,602 & 0,547 & $-0,821$ & 0,411 \\
Caraúbas & $-0,054$ & 0,956 & $-1,051$ & 0,292 \\
Congo & $-0,602$ & 0,547 & $-0,930$ & 0,352 \\
Camalaú & $-0,880$ & 0,378 & $-1,431$ & 0,152 \\
Cabaceiras & $-1,259$ & 0,207 & $-2,642 *$ & 0,008 \\
Barra de São Miguel & $-0,492$ & 0,622 & $-1,587$ & 0,112 \\
São Sebastião do Umbuzeiro & $-0,930$ & 0,352 & $-1,113$ & 0,265 \\
São João do Tigre & $-0,660$ & 0,508 & $-1,040$ & 0,298 \\
São Domingos do Cariri & $-1,149$ & 0,250 & $-1,697$ & 0,089 \\
Ouro Velho & $-0,602$ & 0,547 & $-0,930$ & 0,352 \\
Amparo & $-0,164$ & 0,869 & $-1,259$ & 0,207 \\
\hline
\end{tabular}

(*) Tendência negativa significante ao nível de 5\% de probabilidade. 


\section{ANÁLISE DA EVOLUÇÃO ESPACIAL DO ALBEDO E DA COBERTURA VEGETAL DA SUPERFÍCIE}

Na Figura 8 está espacializada a estatística Z do teste de Mann-Kendall para as duas variáveis. Observa-se a tendência negativa do índice de vegetação (Figura 8A) nas regiões que correspondem os municípios de Monteiro e Cabaceiras. O núcleo com tendência crescente está localizado na região dos municípios de Coxixola e Serra Branca. Em relação ao albedo (Figura 8B) a tendência é decrescente para todos os municípios, com destaque para a região do município de Cabaceiras. Esse decréscimo do albedo justifica-se, em partes, pela quase inexistência de anos secos no período estudado (2000-2013), havendo assim cobertura do solo na maior parte do período estudado. Nos anos secos (2012 e 2013) observa-se o aumento dos valores do albedo (Figura 8B).
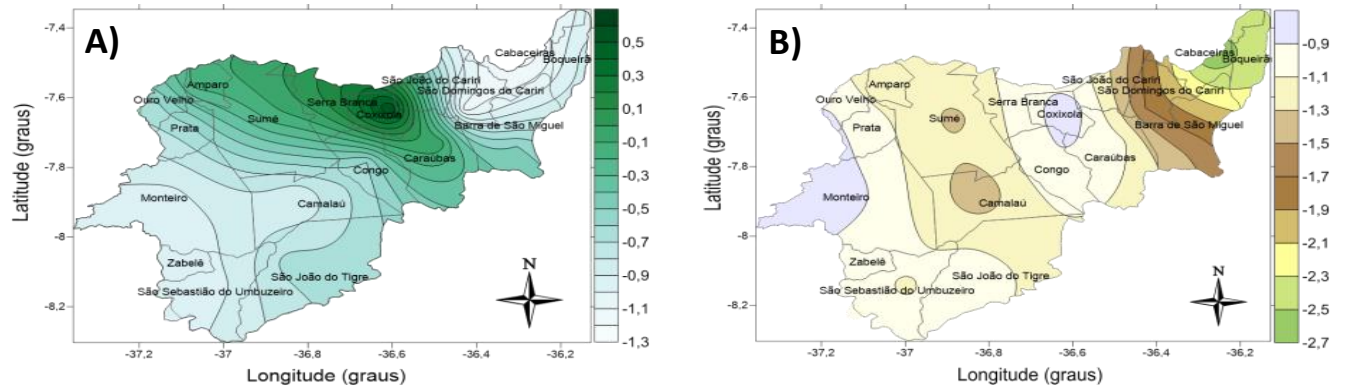

Figura 8: Distribuição espacial da estatística Z do teste de Mann Kendall (MK) para o Índice de vegetação ajustado ao solo - IVAS (A) e albedo da superfície (B), período (2000-2013) para o alto curso da bacia hidrográfica do Rio Paraíba.

Em relação à distribuição espacial dos valores médios do índice de vegetação (IVAS) observa-se que os valores decrescem de noroeste e nordeste para a porção central (Figura 9A). O município de Congo apresenta os menores índices, o que pode estar relacionado com um uso inadequado do solo bem como elevado quantitativo de rebanhos neste município, elementos que acentuam o processo de degradação das terras. Os municípios de Amparo e Prata apresentam os picos com valores máximos de vegetação. Em relação ao albedo da superfície (Figura 9B), o núcleo com valores mais elevados coincide com as áreas de ocorrência de menor IVAS. O albedo diminui no sentido sudoeste da bacia, com valores mínimos em São Sebastião do Umbuzeiro. A combinação dessas duas variáveis pode indicar que há nessa área um processo mais intenso de degradação das terras, com áreas de solo exposto, que é possível identificar através de imagens orbitais e que foram visualizadas em trabalho de campo.

De acordo com o PAE-PB (2011) cerca de 60\% e 70,7\% das áreas das microrregiões do Cariri Ocidental e Oriental, respectivamente, estão com alto nível de desertificação. 
Destaca-se os municípios de Caraúbas, Gurjão, Santo André, Barra de São Miguel, São José dos Cordeiros, Taperoá, Parari, Serra Branca, Coxixola, Congo, Camalaú e São João do Tigre como os municípios mais degradados. Nessas regiões ocorrem as menores precipitações pluviais, proporcionando maior vulnerabilidade ao uso mais intenso das terras, seja agrícola ou agropecuário.
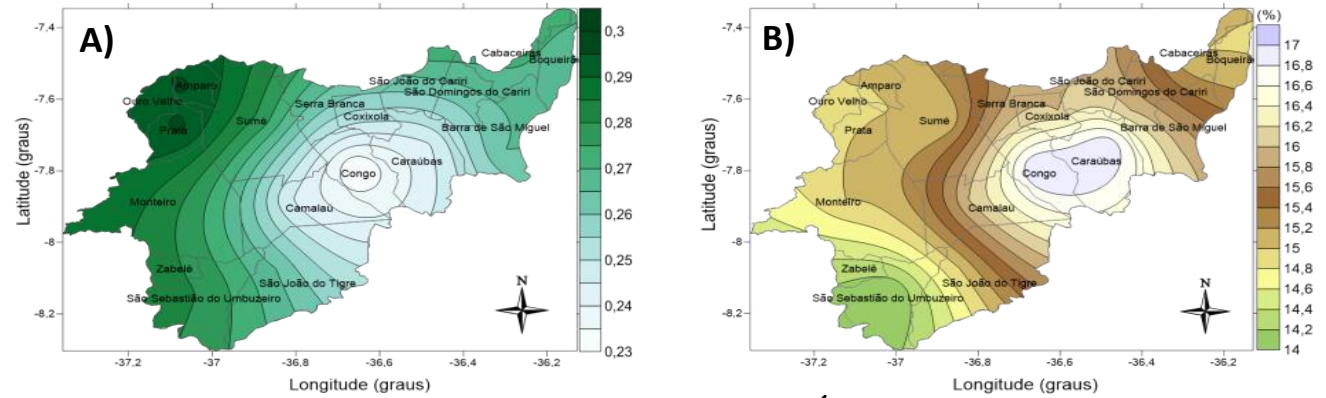

Figura 9: Distribuição espacial dos valores médios do Índice de vegetação ajustado ao solo IVAS (A) e do albedo da superfície (B) no alto curso da bacia hidrográfica do Rio Paraíba.

Quando analisado sazonalmente, o IVAS varia de acordo com o período seco e chuvoso para a região. Essa constatação também foi demonstrada por Bezerra et al., (2014) ao identificar, em região semiárida do Rio Grande do Norte, valores de IVDN entre 0,20 e 0,30 no período seco e 0,60 a 0,80 no período chuvoso. Apesar da variação do índice de vegetação estar condicionada à variação da precipitação pluvial, as localidades (Congo , Camalaú e Caraúbas) não coincidem com as menos chuvosa da bacia hidrográfica (Figura 10).

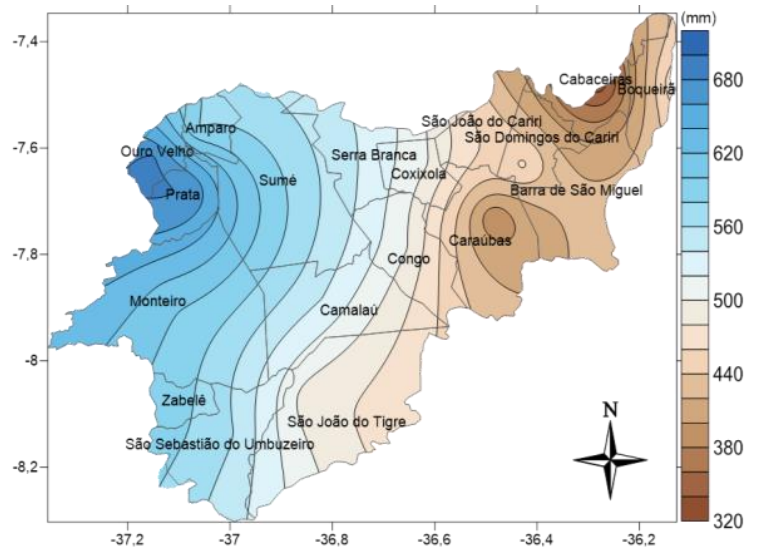

Figura 10: Distribuição espacial da precipitação pluvial.

Fonte: Alves et al., 2015 


\section{COMPARAÇÃO DO ÍNDICE DE VEGETAÇÃO E ALBEDO DA SUPERFÍCIE PARA ANOS: SECO E CHUVOSO}

As Figuras 11 e 12 referem-se à distribuição mensal do índice de vegetação ajustado ao solo (IVAS) e do albedo da superfície para o ano seco (2013) e chuvoso (2008), respectivamente. Em relação à imagem do dia 30/09 (Figura 10) observa-se que mais de 50\% da área apresenta IVAS entre 0,8 e 0,16. Tal evidência relaciona-se a época de imageamento da região, que corresponde ao período de precipitações pluviais mínimas, e também devido à própria vegetação da área, formada por caatinga caducifólia arbustiva, que se caracteriza pela queda das folhas no período seco (agosto a dezembro).

É importante destacar que nos meses de maio, junho e julho, a presença de vegetação está mais concentrada nas proximidades do reservatório hídrico "Epitácio Pessoa" e na Área Proteção Ambiental (APA) das Onças, município de São João do Tigre. No primeiro caso a explicação está relacionada à existência de áreas irrigadas com desenvolvimento permanente de culturas no entorno do reservatório, não correspondendo à existência de vegetação nativa. No segundo caso a razão é o relevo, pois coincide com as áreas mais elevadas e com maior declividade, pois o acesso e a utilização dessas áreas para fins agropecuários são mais limitados. Quando avaliado temporalmente, o IVAS pode ser importante indicador de desertificação e de redução de fitomassa da Caatinga (SAMPAIO et al., 2003; RODRIGUES, et al., 2009).

Os municípios que apresentaram menores índices de vegetação foram Congo, Caraúbas e Camalaú. Certamente nestes municípios, as ações antrópicas relacionadas à degradação das terras são mais acentuadas. Nesses municípios ocorrem as maiores áreas de solo exposto (IVAS entre 0,0 e 0,16 ) e vegetação arbustiva aberta baixa (IVAS entre 0,16 e $0,24)$.

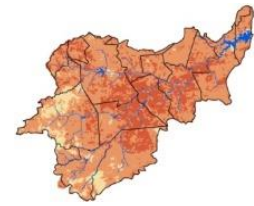

25/01

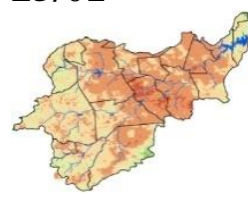

17/05

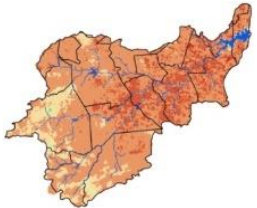

$02 / 02$

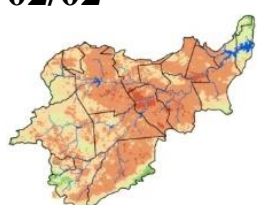

18/06

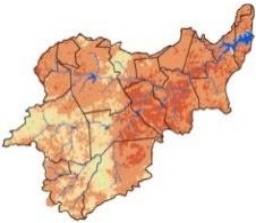

$30 / 03$

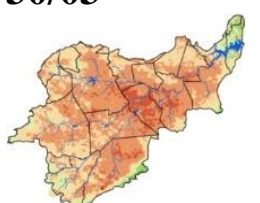

20/07

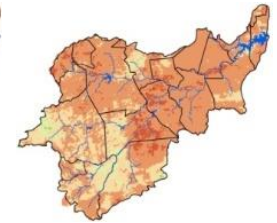

07/04

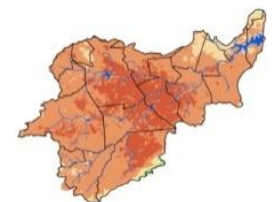

21/08 


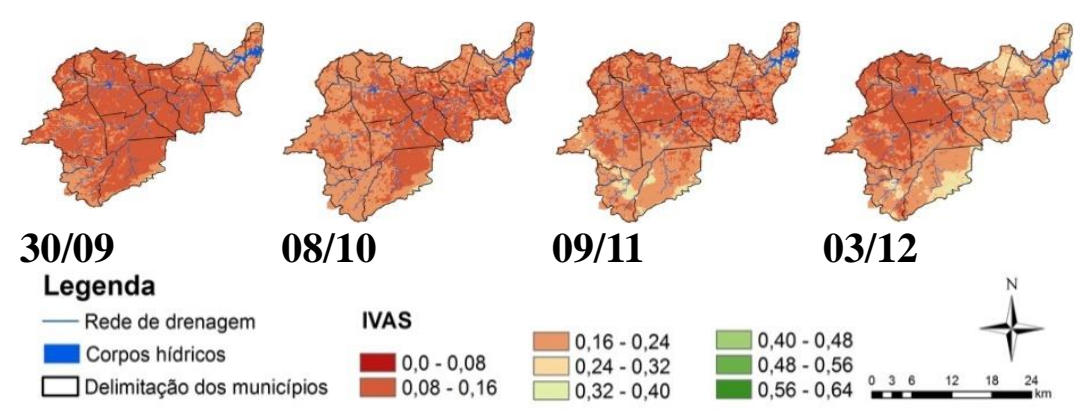

Figura 11: Carta temática do comportamento sazonal do índice de vegetação ajustado ao solo (IVAS) na da bacia hidrográfica do alto curso do Rio Paraíba, durante o ano de 2013. Fonte: Alves \& Azevedo (2015).

Na Figura 12 observa-se a caracterização da vegetação no ano chuvoso de 2008 . Na imagem do dia 06/04 verifica-se que 38\% da área apresentou valores de IVAS entre 0,48 e 0,56 e $36 \%$ valores entre 0,40 e 0,48, demonstrando uma vegetação de porte mais arbóreo e principalmente em condições mais favoráveis de suprimento hídrico, portanto com maior vigor, pois a imagem foi obtida no período da estação chuvosa. Esse comportamento permanece até os meses de maio e junho.

Govaerts \& Lanttazio (2008) explicam que na relação entre vegetação e a precipitação há um atraso de cerca de um mês na resposta da vegetação a variação da umidade do solo resultante da acumulação de água no sistema radicular da planta. Por sua vez, o albedo de superfície apresenta mudanças distintas diretamente resultantes das variações de biomassa e de umidade da superfície. Ressalta-se a importância de demonstrar o comportamento sazonal dos índices de vegetação devido à predominância de meses secos influenciarem o valor médio apresentado.
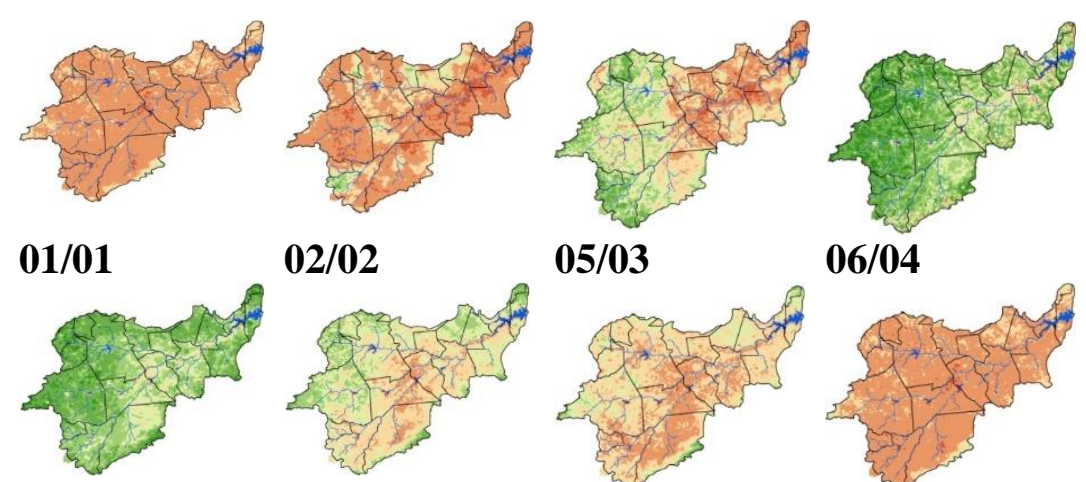

$02 / 02$

$05 / 03$

$06 / 04$
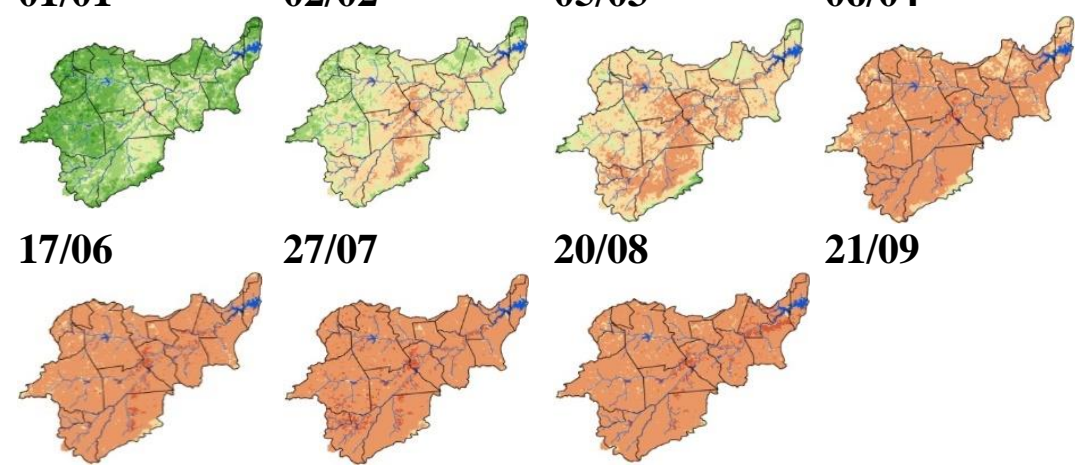

27/07

20/08

21/09

23/10
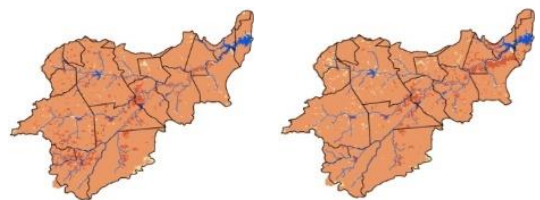

16/11

10/12 


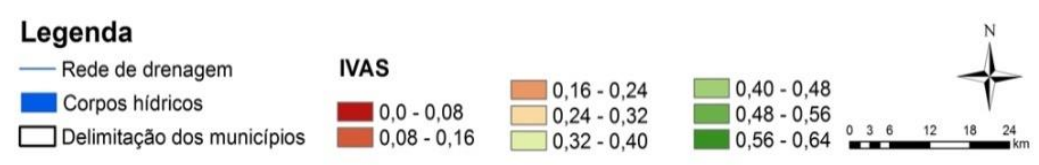

Figura 12: Carta temática do comportamento sazonal do Índice de vegetação ajustado ao solo - IVAS no alto curso da bacia hidrográfica do Rio Paraíba, durante o ano de 2008.

Fonte: Alves \& Azevedo (2015).

É importante mencionar que em alguns casos onde o índice de vegetação é elevado correspondem a campos de Prosopis Juliflora ( $S w$ ) (algaroba), uma vez que o IVAS não envolve detecção de mudanças de composição de espécies. A algaroba (Figura 13A) é uma espécie exótica, introduzida no bioma Caatinga e que apresentou elevada adaptabilidade à região, devido a um sistema radicular que se aprofunda no solo por vários metros e que é especializado em aproveitar a água armazenada nessa região. Essa espécie tem competido com o desenvolvimento de espécies nativas, especialmente em regiões de planícies aluviais. Em estudo realizado no semiárido, foram constatados pontos isolados que apresentaram IVDN próximos a 0,80 e que representam espécies nativas e exóticas, como o Zizyphus joazeiroMart (Juazeiro) e a Prosopis juliflora, que apresentam alta densidade foliar (RODRIGUES et. al. 2009).
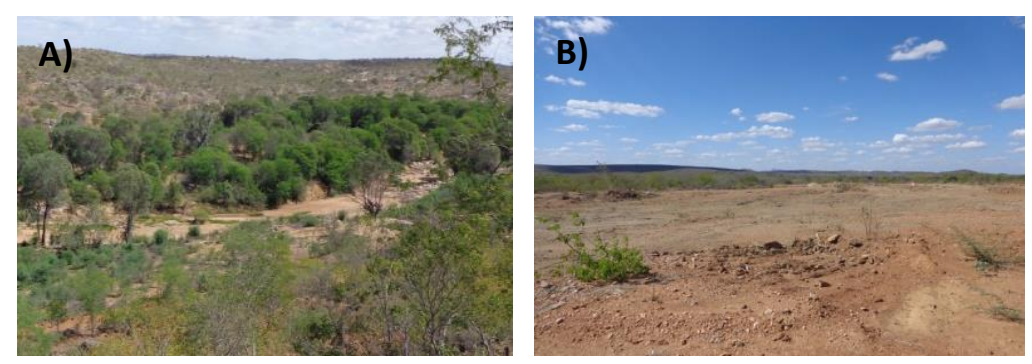

Figura 13: Presença de algaroba nas margens do Rio Paraíba, município de Caraúbas-PB (A) e áreas de solo exposto no município de Congo (B). Trabalho de campo realizado em setembro de 2014.

Gallaher \& Merlin (2010), em estudo realizado no Havaí, relatam tanto impactos negativos da algaroba sobre o ambiente quanto positivos, particularmente sobre áreas degradadas, facilitando o processo de sucessão vegetal, sendo seu uso indicado em esforços de reflorestamento. Nota-se, contudo, que os algarobais se concentram em solos aluviais, que correspondem, na maioria dos casos, a áreas agrícolas que foram abandonadas e rapidamente ocupadas por esta espécie, e que deveriam ter a mata ciliar preservada.

As espécies reconhecidas como predominantes em áreas em processo de desertificação (Catingueira, Jurema preta, etc.) foram identificadas em grande quantidade em praticamente 
todos os municípios da área de estudo, além de muitas áreas com presença de solo exposto (Figura 12B).

Da mesma forma que o índice de vegetação, o albedo da superfície, quando avaliado de forma sazonal e em longo prazo, pode ser importante indicador de desertificação e de redução de biomassa da Caatinga (Bezerra et. al. 2014). As Figuras 14 e 15 detalham a variação sazonal da distribuição espacial do albedo da superfície em ano seco e chuvoso, respectivamente.

Os valores máximos foram detectados nos meses de fevereiro, outubro e novembro (Figura 13) nas áreas de solo exposto (24 a 41\%), correspondentes aos municípios de Caraúbas, Congo, Coxixola, Barra de São Miguel, São Domingos e São João do Cariri. A explicação para esses valores é a perda da parte aérea do dossel foliar durante a estação seca e/ou retirada da vegetação natural para usos antrópicos. Ressalta-se, contudo, que os valores máximos ocorrem em determinadas épocas do ano, portanto, não é uma condição permanente na área de estudo. Em termos médios, esses valores são suavizados.

Valores equivalentes foram identificados por outros autores: Silva et al. (2005) observaram, em duas imagens TM Landsat5 envolvendo áreas de vegetação nativa nos municípios de Petrolina, PE e Juazeiro, BA, albedos de superfície de 31\% e 33\%; Rodrigues et. al. (2009) utilizando imagem Landsat7 ETM+ estimaram que aproximadamente $14 \%$ da área total apresentou albedos da superfície variando de 26 a 36\% e Bezerra et al. (2014) detectaram os maiores valores nas áreas de solo exposto (30 a 35\%).

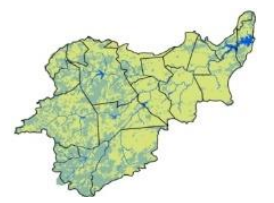

25/01

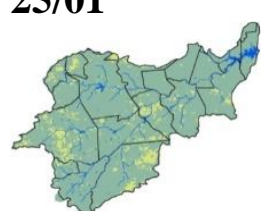

$17 / 05$

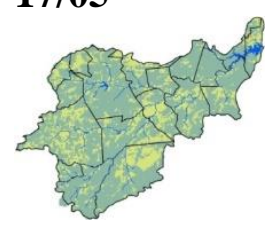

30/09

Legenda
Rede drenagem
$\square$ Delimitação dos
Corpos hídricos
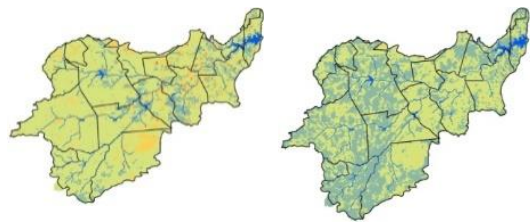

$30 / 03$

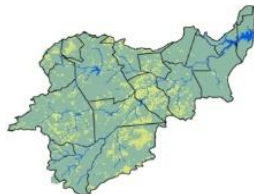

$18 / 06$

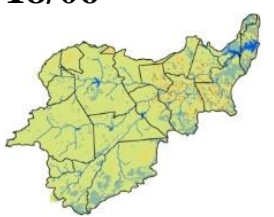

08/10

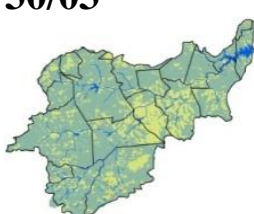

20/07

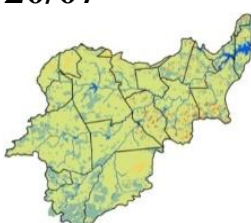

09/11

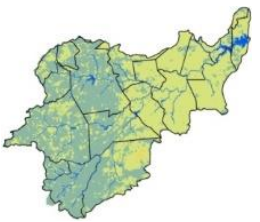

07/04

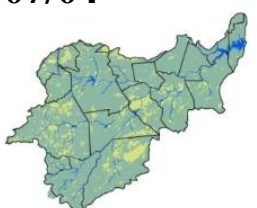

21/08

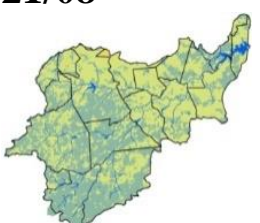

03/12

Albedo (\%)
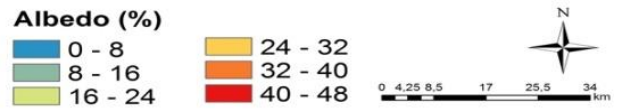

Figura 14: Carta temática do comportamento sazonal do albedo da superfície na região do 
alto curso da bacia hidrográfica do Rio Paraíba, durante o ano de 2013.

Os baixos valores de albedo (0 a 8\%) identificados nas figuras indicam a presença de copos hídricos na região, tais como: Açude Epitácio Pessoa, localizado no município de Boqueirão, Açude Campos, localizado no município de Caraúbas, Açude Cordeiro, município do Congo, Açude Camalaú, município de Camalaú, Açude de Sumé, município de Sumé, Açude Poções em Monteiro e Açude Santo Antônio, município de São Sebastião do Umbuzeiro.

Para áreas com cobertura vegetal de Caatinga o albedo variou de 8 a 16\% (Figura 14), corroborando com os valores de 10 a $15 \%$ obtidos por Bezerra et al. (2014), 12 e $21 \%$ por Cunha et al. (2012) e Lima et al. (2009) para regiões de Caatinga.

Wang \& Davidson (2007) afirmam que as condições hídricas do solo e da planta influenciam diretamente nos padrões sazonais do albedo. O solo mais úmido absorve mais radiação eletromagnética e, por estar mais úmido (escuro), reduz a refletância, diminuindo os valores do albedo. Govaerts \& Lantazzio (2008) demonstraram que o déficit de precipitação nos meses junho, julho, agosto, setembro e outubro que ocorreu entre as latitudes $12^{\circ} \mathrm{N}$ e $18^{\circ} \mathrm{N}$ (região do Sahel africano) traduziu-se num aumento de albedo da superfície de cerca de 6\%. Nas imagens de 23/10 e 16/11 (estação seca), observa-se também um aumento nos valores de albedo da superfície de cerca de $4 \%$.
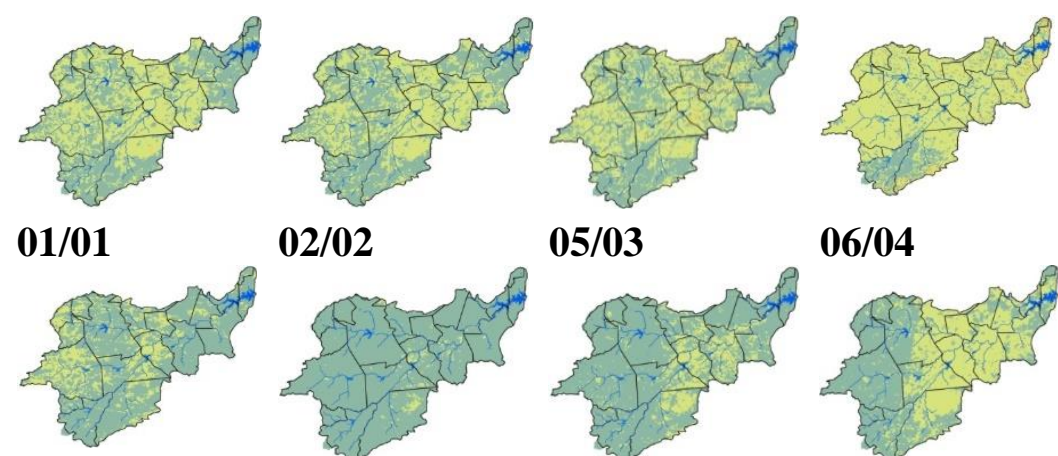

$02 / 02$

$05 / 03$

$06 / 04$
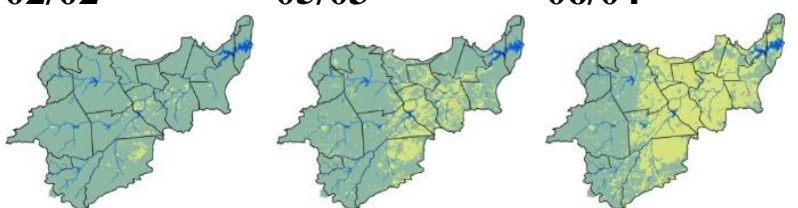

17/06

27/07

$20 / 08$

21/09
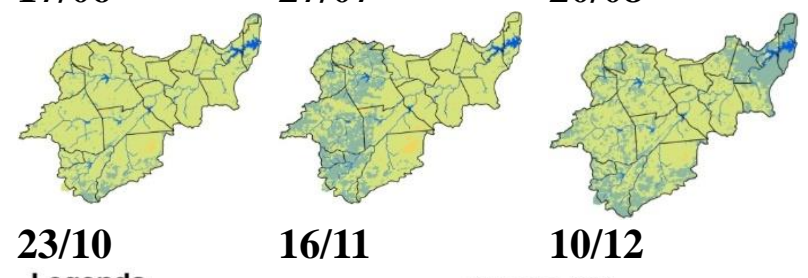

16/11

$10 / 12$
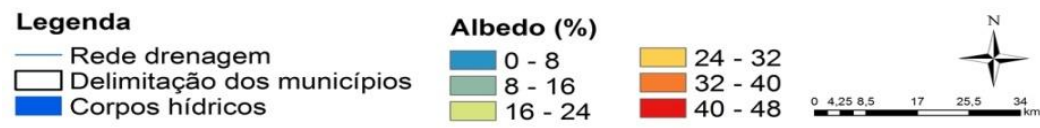

Figura 15: Carta temática do comportamento sazonal do albedo da superfície no alto curso da bacia hidrográfica do Rio Paraíba, durante o ano de 2008. 
Li et al., (2000) mostraram que o albedo da superfície do solo é um fator importante para os mecanismos da desertificação. Em estudo realizado na região semiárida da China, por meio de experimento conduzido em parcelas de pastagem sem pastoreio, com pastoreio leve, moderado e intensivo de ovelhas, a remoção ou redução da cobertura vegetal causada pelo pastoreio aumentou o albedo da superfície. A experiência demonstrou que, com o aumento da intensidade de pastoreio, os valores de albedo tendem a aumentar e os saldos de radiação líquida disponível tendem a diminuir. Além disso, informam que pode existir um valor crítico de albedo da superfície, acima do qual a desertificação é provável de acontecer. Este valor é cerca de $30 \%$ para as pastagens arenosas estudadas por eles.

A região da bacia hidrográfica do alto curso do Rio Paraíba é caracterizada por acentuado pastoreio de rebanhos caprinos, ovinos e bovinos, manejados de forma extensiva, que contribuem para a remoção da cobertura vegetal durante o ano inteiro. Além disso, boa parte da vegetação lenhosa, predominantemente algarobais, é retirada para suprimento energético (lenha e carvão) e consequente comercialização, principalmente com o estado vizinho (Pernambuco), responsável por alta demanda.

\section{CONSIDERAÇÕES FINAIS}

Os resultados da evolução espaço-temporal do índice de vegetação ajustado ao solo (IVAS) e do albedo da superfície da bacia hidrográfica do alto curso do Rio Paraíba permitem concluir que:

1) $\mathrm{O}$ albedo e índice de vegetação da superfície têm seus valores influenciados pela sazonalidade climática da região. A precipitação pluvial é o elemento que desencadeia o aumento do índice de vegetação e diminuição do albedo da superfície, considerando-se que estas duas variáveis têm comportamento inverso.

2) O núcleo central do alto curso da bacia hidrográfica do Rio Paraíba (municípios de Congo, Camalaú e Caraúbas) apresentou baixo índice de vegetação e elevado albedo da superfície. O baixo índice de vegetação nessa região pode estar relacionado ao processo de degradação das terras, uma vez que quanto menor o índice de vegetação maior a suscetibilidade à degradação das terras.

3) Ao longo do período analisado (2000-2013), ambas as variáveis (índice de vegetação e albedo) apresentaram tendência decrescente, mas não significativa ao nível de significância de $\alpha=0,05$, evidenciando o aumento pouco significativo da degradação das terras. 


\section{REFERÊNCIAS BIBLIOGRÁFICAS}

ACCIOLY, L. J. O.; PACHECO, A.; COSTA, T.C.C.; LOPES, O.F.; \& OLIVEIRA, M.A.J. Relações empíricas entre a estrutura da vegetação e dados do sensor TM/LANDSAT. Revista Brasileira de Engenharia Agrícola e Ambiental, Campina Grande, v. 6, n. 3, p. 492-498, 2002.

ALVES, J. J. A.; SOUZA, E. N.; NASCIMENTO, S. S. Núcleos de desertificação no estado da Paraíba. Revista RA'E GA, n. 17, p. 139-152, 2009.

ALVES, T. L. B.; AZEVEDO, P. V. de FARIAS, A. A. de (2015). Comportamento da precipitação pluvial e sua relação com o relevo nas microrregiões do Cariri Oriental e Ocidental do estado da Paraíba. Revista Brasileira de Geografia Física, v.8, n. 6, p.16011614, 2015.

ALVES, T. L. B. \& AZEVEDO, P. V. de (2015). Análise da variação espacial e temporal do índice de vegetação e sua relação com parâmetros climáticos na bacia hidrográfica do alto curso do Rio Paraíba, Estado da Paraíba, Brasil, Boletim Goiano de Geografia, v. 35, n. 3, p. 530-553, 2015.

ALVES, T. L. B., AZEVEDO, P. V. de, SANTOS, A. C. C. Influence of climate variability on land degradation (desertification) in the watershed of the upper Paraíba River. Theoretical and Applied Climatology, [on-line], 2015.

AQUINO, C. M. S. de; ALMEIDA, J. A. P. de \& OLIVEIRA, J. G. B. de. Estudo da cobertura vegetal/uso da terra nos anos de 1987 e 2007 no núcleo de degradação/desertificação de São Raimundo Nonato - Piauí. Revista RA'E GA, v. 25, p. 252278, 2012.

BACK, J. A. Aplicação de análise estatística para identificação de tendências climáticas. Pesquisa Agropecuária brasileira. Brasília, v. 36, n. 5, p. 717-726, 2001.

BARBOSA, H. A.; HUETE, A.R. \& BAETHGEN, W.E. A 20-years study of NDVI variability over the Northeast Region of Brazil. Journal of Arid Environments, 2006, v. 67, p. 288-307.

BEZERRA, J. M.; MOURA, G. B. de A.; SILVA, B. B. da; LOPES, P. M. O. \& SILVA, E. F. de F. Parâmetros biofísicos obtidos por sensoriamento remoto em região semiárida do estado do Rio Grande do Norte, Brasil. Revista Brasileira de Engenharia Agrícola e Ambiental, v. 18, n. 1, p. 73-84, 2014.

BOTELLHO, R. G. M. \& SILVA, A. S. da. Bacia Hidrográfica e Qualidade Ambiental. In: VITTE, Antonio C.; GUERRA, Antonio José T. (Orgs.). Reflexões sobre a Geografia Física no Brasil. Rio e Janeiro: Bertrand Brasil, 2004. p. 153 - 188.

BRASIL. Ministério do Meio Ambiente (MMA). Programa de Ação Nacional de Combate à Desertificação e Mitigação dos Efeitos da Seca, PAN-BRASIL. Convenção das Nações Unidades de Combate à Desertificação e Mitigação dos Efeitos da Seca - CCD. Brasília: MMA, 2004. 225p.

CASTANHO, R. B.; CASSOL, R. \& BEZZI, M. L. A modernização agrícola e o uso de técnicas de geoprocessamento no uso da terra em dois distritos de Palmeira das Missões-RS. Geosul, v. 19, n. 38, p. 159-183, 2004.

CONTI, J. B. A questão climática do nordeste brasileiro e os processos de desertificação.

Revista Brasileira de Climatologia, v. 1, n. 1, p. 7-14, 2005.

CONTI. Clima e meio ambiente. 7 ed. São Paulo: Atual, 2011.96 p.

CUNHA, J. E. de B. L.; RUFINO, I. A. A. SILVA, B. B. da e CHAVES, I. de B. Dinâmica da cobertura vegetal para a Bacia de São João do Rio do Peixe, PB, utilizando-se sensoriamento remoto. Revista Brasileira de Engenharia Agrícola e Ambiental, v.16, n.5, p.539-548, 2012. 
GALLAHER, T. \& MERLIN, M. Biology and Impacts of Pacific Island Invasive Species. 6. Prosopis pallida and Prosopis juliflora (Algarroba, Mesquite, Kiawe) (Fabaceae). Pacific Science, v. 64, 489-526, 2000.

GIONGO, P. R. \& VETTORAZZI, C. A. Albedo da superfície por meio de imagens TMLandsat 5 e modelo numérico do terreno. Revista Brasileira de Engenharia Agrícola e Ambiental, v.18, n.8, p. 833-838, 2014.

GOVAERTS, Y. \& LATTANZIO, A. Estimation of surface albedo increase during the eighties Sahel drought from Meteosat observations. Global and Planetary Change, v.64, n. 3, p. 139-145, 2008.

YANG, X.; ROST, K.T.; LEHMKUHL, K. \& ZHU, Z. The evolution of dry lands in northern China and in the Republic of Mongolia since the Last Glacial Maximum. Quaternary International, v.118-119, 69-85, 2004.

KOGAN, F.N. Global drought detection and impact assessment from space. In: WILHITE, D.A. (Ed.), Drought: A Global Assessment, v. 1. Rutledge, London. 2000.

LI, S. G.; HARAZONO, Y.; OIKAWA, T.; ZHAO, H. L.; HE, Z. Y.; CHANG, X. L. Grass land desertification by grazingand the resulting micrometeorological changes in Inner Mongolia. Agricultural and Forest Meteorology, v. 102, p. 125-137, 2000.

LIMA, P. C. S.; LEITÃO, M. M. V. B. R.; AZEVEDO, P. V.; OLIVEIRA, G.M.; ESPÍNOLA SOBRINHO, J.; MOURA, M. S. B.; MENEZES, H. E. A.; PINTO, M. G. C. L. Albedo de pastagem e caatinga. In: Congresso Brasileiro de Agrometeorologia, 16, 2009, Belo Horizonte. SBA/UFV/Embrapa Milho e Sorgo, 2009. Anais... CD ROM. 18 Mai. 2009.

LOPES, H.; CANDEIAS, A.L.B.; ACCIOLY, L.J.O.; SOBRAL, M. do C.M. \& PACHECO, A.P. Parâmetros biofísicos na detecção de mudanças na cobertura e uso do solo em bacias hidrográficas. Revista Brasileira de Engenharia Agrícola e Ambiental, v.14, n.11, p.1210 1219, 2010.

MACHADO, C. C. C.; GALVÍNCIO, J. D.; OLIVEIRA, T. H. de. Análise espacial e temporal do IVAS e do albedo da superfície no município de São José do Sabugi - PB, Geografia, Rio Claro, v. 36, n. 2, p. 359-369, 2011.

MAGAlHÃES, I. A. L.; XAVIER, A. C. \& SANTOS, A. R. Caracterização da dinâmica espectro temporal florestal e da cana-de-açúcar no município de Itapemirim, ES. Geosul, v. 20, n.39, p. 65-82, 2005.

MELO, E. T.; SALES, M. C. L.; OLIVEIRA, J.G.B. Aplicação do Índice de Vegetação por Diferença Normalizada (NDVI) para análise da degradação ambiental da microbacia hidrográfica do Riacho dos Cavalos, Crateús-CE. Revista RA'EGA, Curitiba, v.23, p. 520533, 2011.

MENDONÇA, F.; DANNI-OLIVEIRA, I. M. Climatologia: noções básicas e climas do Brasil. São Paulo: Oficina de Textos, 2007. 206 p.

PAE-PB - Programa de Ação Estadual de Combate à desertificação e Mitigação dos Efeitos da Seca no Estado da Paraíba. João Pessoa: Secretaria de Estado dos Recursos Hídricos, MMA/MCTI/ SUDEMA, 2011. 144p.

PONZONI, F. J.; SHIMABUKURO, Y. E. \& KUPLICH, T. M. Sensoriamento remoto da vegetação. 2 ed. São Paulo: Oficina de Textos, 2012. 160 p.

RODRIGUES, J. O.; ANDRADE, E. M. de; TEIXEIRA, A. dos S. \& SILVA, B. B. da. Sazonalidade de variáveis biofísicas em regiões semiáridas pelo emprego do sensoriamento remoto. Revista Brasileira de Engenharia Agrícola e Ambiental, v. 29, n. 3, p. 452-465, 2009.

SÁ, I. I. S.; GALVÍNCIO, J. D.; MOURA, M.S.B.; \& SÁ, I. B. Cobertura vegetal e uso da terra na região Araripe pernambucana. Mercator, v.9, n. 19, 2010. 
SAMPAIO, E.V.S.B.; Sampaio, Y.; Vital, T.; Araújo, M.S.B. \& Sampaio, G.R.. Desertificação no Brasil: conceitos, núcleos e tecnologias de recuperação e convivência. Recife, Ed. Universitária da UFPE, 2003.

SALES, M. C. L. Evolução dos estudos de desertificação no nordeste brasileiro. Revista GEOUSP, São Paulo, n. 11, p. 115-126, 2002.

SANTOS, E. G. dos, SANTOS, C. A. C. dos e BEZERRA, B. G. Analysis of environmental parameters in Gilbués - PI using satellite images. Journal of Hyperspectral Remote Sensing, v. 4, n. 4, p. 100-110, 2014.

SILVA, B.B.; LOPES, G.M.; AZEVEDO, P.V. Balanço de radiação em áreas irrigadas utilizando imagens LANDSAT 5-TM. Revista Brasileira de Meteorologia, São José dos Campos, v.20, n.2, p.243-252, 2005.

SOUZA, B. I. ; SUERTEGARAY, D. M. A.; LIMA, E. R. V. de. Políticas Públicas, uso do solo e desertificação nos Cariris Velhos (PB/Brasil). Scripta Nova, v. 14, v. 311, 2010.

SOUZA, B. I. de; SILANS, A. M. B. P. de \& SANTOS, J. B. dos. Contribuição ao estudo da desertificação na Bacia do Taperoá. Revista Brasileira de Engenharia Agrícola e Ambiental. v. 8, n. 2-3, p. 292-298, 2004.

TASUMI, M.; ALLEN, R. G.; TREZZA, R. At-surface reflectance and albedo from satellite for operational calculation of land surface energy balance. Journal of Hydrologic Engineering, v.13, p.51-63, 2008.

VAREJÃO-SILVA, M. A. Meteorologia e Climatologia. Versão digital, 2. ed. Recife, 2006. $449 \mathrm{p}$.

Recebido em 04 de maio de 2015.

Aceito em 09 de outubro de 2017. 